\title{
Perceção de professores face à educação de alunos com necessidades educativas especiais: um estudo no norte de Portugal
}

\author{
Amanda Fernandes Santos* \\ Luis Miranda Correia** \\ Anabela Cruz-Santos***
}

\section{Resumo}

Atualmente, não apenas professores e pais esperam das escolas uma postura inclusiva, mas toda a sociedade parece compreender e pleitear esta necessidade. Porém, quando falamos em inclusão, estaremos todos a pensar na mesma coisa? Teremos a mesma perceção das necessidadesque a implementação desta filosofia requer? Estasquestões impulsionaram nossa elaboração deste estudo que teve por base a aplicação de um questionário com os objetivos de perceber a forma como os professores vêm a educação de alunos com Necessidades Educativas Especiais (NEE), e de averiguar as perceções dos professores face à inclusão de alunos com NEE nas escolas regulares. Participaram, deste estudo, 249 professores do lo Ciclo do Ensino Básico de 52 Agrupamentos de Escolas do Distrito de Braga, região Norte de Portugal. O questionário é composto por 25 itens, agrupados em três grupos fundamentais: (1) Atitudes; (2) Recursos; e (3) Colaboração. Os resultados obtidos demonstram a existência de diferenças significativas entre alguns itens dos diferentes grupos e as variáveis género, habilitações académicas e experiência profissional dos sujeitos. Os resultados indicam ainda que, embora os participantes reconheçam que é importante implementar a filosofia inclusiva no país, é necessário providenciar mais formação para todos os indivíduos envolvidos na educação de alunos com NEE, bem como ter-se acesso a um conjunto de recursos especializados que possam prover respostas educativas de qualidade para esses alunos.

Palavras-chave: Educação Especial; Inclusão; Educação escolar básica.

\footnotetext{
* Doutoranda em Estudos da Criança e Mestre em Educação Especial pela Universidade do Minho, Braga, Portugal.

** Professor Catedrático Emérito, Universidade do Minho. Presidente do Instituto Português de Dislexia e Outras Necessidades Especiais (IPODINE). Braga, Portugal.

*** Professora Auxiliar do Departamento de Psicologia da Educação e Educação Especial do Instituto de Educação da Universidade do Minho. Braga, Portugal.
} 


\title{
Teachers' perceptions toward the education of students with special needs: a study in the north of Portugal
}

\begin{abstract}
In our days not only teachers and parents hope for the schools to become inclusive, but all the society seems to understand and advocate for this need. However, when we talk about inclusion are we thinking about the same thing? Do we have the same perception of the needs, so that inclusion can really happen? In order to answers these questions a study was conducted using a questionnaire whose main objective was to understand how teachers understand and perceive the education of the pupils with Special Educational Needs (SEN). 249 teachers participated in the study, all from elementary schools located in Braga, Northern Portugal. The questionnaire had 25 items, divided into three main clusters: (1) Attitudes; (2) Resources; and (3) Collaboration. The results showed significant differences between some of the items and the variables gender, academic qualifications and professional experience. Based on these results, this research indicates that, although participants recognize that it is important to implement the philosophy of inclusion in Portugal, it is necessary to provide more training for all individuals involved in the education of students with SEN. They also indicated that there is a lack of specialized human resources needed to provide quality educational responses for the abovementioned students.
\end{abstract}

Keywords: Special Education; Inclusion; Elementary school.

\section{Introdução}

Em Portugal, depois da Revolução dos Cravos (25 de abril de 1974), a educação sofreu uma mudança significativa, levando as escolas do país a abrir as suas portas a todas as crianças. Esta massificação da educação teve como consequência, para além de uma participação muito maior de crianças e adolescentes no ensino público, uma alteração profunda na forma como as crianças com necessidades educativas especiais (NEE) começaram a ser tratadas (CORREIA, 1997a).

Essa alteração tornou-se ainda mais evidente com a publicação do Decreto-Lei n. ${ }^{\circ} 319 / 91$, de 23 de agosto, embora ainda se continuasse a perceber que, quer o ensino regular, quer o que à altura era designado de "ensino especial", operavam em campos distintos, evidenciando situações de segregação e de exclusão denunciadas pelo atendimento de grande parte dos alunos de NEE, particularmente aqueles com NEE significativas, em classes especiais, escolas especiais e instituições. Contudo, a procura de novos processos que viessem a promover o sucesso escolar destes alunos leva ao surgimento de um movimento que pedia a inserção dos alunos com NEE significativas nas classes regulares das escolas das suas residências onde, sempre que possível, lhes deviam ser prestados todos os apoios e serviços especializados de acordo com as suas características, capacidades e necessidades. Surgia, assim, o movimento da inclusão que, em Portugal, começa a receber uma atenção muito especial 
particularmente depois da realização da "Conferência mundial sobre necessidades educativas especiais: Acesso e qualidade", efetuada em Salamanca, em junho de 1994. A Conferência, ao cunhar uma declaração, Declaração de Salamanca, sobre os princípios, as políticas e as práticas que deviam orientar a educação dos alunos com NEE, inspirou-se nos princípios que regiam o movimento da inclusão e no "reconhecimento da necessidade de atuar com o objetivo de conseguir escolas para todos - instituições que incluam todos os indivíduos, aceitem as diferenças, apoiem a aprendizagem e respondam às necessidades individuais de cada um deles" (p.iii).

Nesta linha de ideias, Portugal começa a construir um sistema educativo que considere e possa vir a respeitar o princípio da igualdade de oportunidades, tendo presente a importância de prover uma educação gratuita e de qualidade para todos os alunos com NEE, apropriando-a às características desses mesmos alunos (educação apropriada).

Aqui, será importante sublinhar que terá necessariamente de se deixar de falar em "ensino especial", tido com o um sistema paralelo ao "ensino regular" e começar a entender-se, com o rigor científico e pedagógico exigidos, o genuíno conceito de "educação especial", à luz dos princípios que regem o movimento da inclusão. Dessa forma, ela deve ser entendida como um conjunto de recursos especializados que, através dos serviços que venha a prestar, possibilite à Escola e às famílias responder adequadamente às necessidades de todos os alunos, designada, principalmente, aos alunos com NEE (CORREIA, 1977b). O conceito de Correia parece-nos bastante adequado. Afirma, este autor, que a Educação Especial deve ser vista como um:

[...] conjunto de recurso que devem prestar serviços e apoios especializados destinados a responder às necessidades especiais de um aluno com base nas suas características e com o fim de maximizar o seu potencial. Tais serviços devem efetuar-se, sempre que possível, na classe regular e devem ter por fim a prevenção, redução u supressão da problemática do aluno, seja ela do foro mental, físico ou emocional e/ou a modificação dos ambientes de aprendizagem por forma a que ela possa receber uma educação apropriada às suas capacidades e necessidades. (p. 8)

Por seu turno, a Declaração de Salamanca diz que:

[...] As escolas regulares, seguindo uma orientação inclusiva, constituem os meios mais capazes para combater as atitudes discriminatórias, criando comunidades abertas e solidárias, construindo uma sociedade inclusiva e atingindo a educação para todos... (p. IX)

Assim sendo, com o Decreto-Lei n.. 3/2008, Portugal parece, aparentemente, ter aberto caminho para a inclusão dos "tradicionalmente excluídos", que mais não são, na sua maioria, do que os alunos com NEE significativas. A filosofia do referido decreto-lei parece, portanto, ter por lema o princípio da rejeição zero o qual proclama que nenhum aluno deve ser excluído de uma educação de qualidade, devendo-lhe ser sempre considerados apoios especializados que visem responder às necessidades 
educativas especiais dos alunos, afirmando que estes "podem implicar a adaptação de estratégias, recursos, conteúdos, processos, procedimentos e instrumentos, bem como a utilização de tecnologias de apoio." (p. 155)

Se no papel, leia-se legislação, a inclusão parece tomar forma, fora dele, nas escolas do País, a dúvida permanece, uma vez que para além da inclusão social é deveras importante, no contexto escolar, considerar-se a inclusão acadêmica, a pedir que se responda a um conjunto e questões como, por exemplo:

- Que tipo de atitudes e expectativas devem mudar?

- Que tipo de recursos humanos e materiais devem ser considerados?

- Que tipo de formação (inicial, especializada, contínua) para os docentes?

- Que ratio professor-aluno?

- Que tipo de mudança se deve operar na classe? E na escola?

- Que tipo de envolvimento parental?

Paralelamente, torna-se necessário identificar um conjunto de princípios cujo cumprimento prático dará uma dimensão operativa à crença na inclusão, abrindo caminhos reais e facilitadores da consecução da escola para todos. Neste contexto, a juntar às questões formuladas acima, julga-se determinante contemplar alguns princípios como, por exemplo:

- Existência de um compromisso perante a filosofia da inclusão por parte da liderança e de todos aqueles envolvidos no processo educativo, docentes e pais;

- Entender a escola como uma organização com um projeto definido;

- Disponibilização de redes de apoio especializado, a nível individual, quando necessário;

- Introdução de práticas onde impere a diversidade curricular;

- Cultura permanente de práticas de colaboração entre todos os agentes educativos.

Do que foi dito ressalta que os caminhos para a construção de uma escola para todos não são fáceis, nem de conceber, nem de concretizar. São, pelo contrário, complexos na sua formulação e complicados na sua implementação, mesmo quando as vontades estão presentes. A este propósito é interessante e preocupante referir as palavras de Mary Warnock (2005), uma referência na área das NEE e dos movimentos integradores e inclusivos, que, num documento que enviou à PhilosophyofEducationSocietyof Great Britain, chegou a conclusão de que o conceito de inclusão, tal como é interpretado por muita gente, causa "confusão da qual as crianças são as vítimas". Diz ainda que, "O ideal da inclusão brotou de corações no seu lugar", mas descreve a sua implementação como "um legado desastroso". 
Nesse contexto, prefigura-se pertinente a elaboração de estudos suscetíveis de contribuir para o aprofundamento reflexivo das várias questões que levam à construção de uma escola para todos, na qual os direitos dos alunos com NEE significativas sejam assegurados com base no reforço de atitudes e dinâmicas de implementação de culturas organizacionais e pedagógicas inclusivas. É, pois, nesta perspetiva que se enquadra o presente estudo, embora tenha apenas como sujeitos, numa primeira fase, os docentes do ensino regular e de educação especial. Este facto deve-se ao pressuposto, como afirmam Correia e Martins (2000), de que, "Com o incremento das práticas inclusivas, assiste-se a um muito maior envolvimento do professor do ensino regular no atendimento a alunos com NEE e a uma alteração significativa do papel do professor de educação especial" e continuam, "... os professores desempenham um papel preponderante no que diz respeito ao sucesso das práticas inclusivas e as suas atitudes parecem estar directamente relacionadas com os seus comportamentos" (p. 17).

Assim, com este estudo pretendemos compreender as perceções dos professores face à inclusão de alunos com NEE nas escolas públicas e, sempre que possível, nas classes dessas mesmas escolas, tendo por base as atitudes de um grupo de 249 professores do $1^{\circ}$ Ciclo do Ensino Básico do Distrito de Braga.

Para que fosse possível analisar as perceções dos professores este questionário foi elaborado tendo, por base três grupos de itens, considerados fundamentais para que a filosofia da educação inclusiva possa vir a concretizar-se plenamente, nomeando as atitudes, os recursos e a colaboração.

\section{Participantes}

A amostra do estudo é constituída por 249 professores do lo Ciclo do Ensino Básico de 52 Agrupamentos de Escolas do Distrito de Braga.

Dos 249 professores, 202 (81\%) são do gênero feminino e 47 (19\%) do gênero masculino, com idades compreendidas entre os 27 e os 62 anos de idade $(\mathrm{M}=44$; $\mathrm{DP}=640$ ). Quanto ao tempo de experiência profissional, os participantes têm desde menos de 5 anos até mais de 30 anos de carreira ( $M=$ entre 16 e 20 anos; $\mathrm{DP}=1,592)$. No que respeita à formação acadêmica, os participantes possuem habilitações desde curso do magistério primário até doutoramento, sendo a maioria $(65,5 \%)$ detentora do grau de licenciatura.

\section{Instrumento}

Nesse estudo foi utilizado o questionário elaborado por Correia (2008) "Perceção dos professores quanto à educação de alunos com Necessidades Educativas Especiais". O instrumento foi construído com o intuito de conhecer as perceções dos professores do ensino regular, no que diz respeito à educação de alunos com NEE nas escolas do 1º Ciclo do Ensino Básico. 
Esse questionário é constituído por duas partes, a primeira é referente aos dados sociodemográficos, que engloba as variáveis do género, idade, habilitações académicas, tempo de experiência profissional e a qual Agrupamento de Escolas pertence. A segunda parte é composta por 25 itens, divididos por três grupos, relativos às perceções dos professores quanto à educação de alunos com NEE. Os itens são classificados com base na escala de Likert, com quatro opções de resposta, nomeadamente: concordo plenamente (CP), concordo (C), discordo (D) ou discordo plenamente (DP).

O questionário contém, ainda, a explicação do seu objetivo e a garantia de anonimato e confidencialidade no tratamento dos dados.

\section{Procedimentos}

Todos os Agrupamentos de Escolas do Distrito de Braga foram contactados pelos pesquisadores de forma a requerer que encaminhassem o questionário, disponibilizado online, aos professores do lo Ciclo do Ensino Básico.

\section{Resultados}

\section{Análise Descritiva}

A seguir serão apresentados os dados segundo uma análise descritiva, divididos em três grupos, nomeadamente: atitudes, recursos, e colaboração.

O primeiro grupo engloba os itens $1,2,4,7,11,13,14,15,16,20,21$ e 22, e refere-se às atitudes dos professores face à inclusão de alunos com NEE nas classes regulares. O quadro 1 ilustra a frequência absoluta das respostas dos participantes.

Quadro 1 - Atitudes

\begin{tabular}{l|c|c|c|c|c|c|c|c}
\hline \multicolumn{1}{c|}{ Item } & \multicolumn{2}{c|}{ DP } & \multicolumn{2}{c|}{ D } & \multicolumn{2}{c|}{ C } & \multicolumn{2}{c}{ CP } \\
\hline $\begin{array}{l}\text { l. Todos os alunos, incluin- } \\
\text { do os alunos com Necessi- } \\
\text { dades Educativas Especiais } \\
\text { (NEE), têm o direito de } \\
\text { aprender juntos. }\end{array}$ & 3 & $1,2 \%$ & 16 & $6,4 \%$ & 120 & $48,2 \%$ & 110 & $44,2 \%$ \\
\hline $\begin{array}{l}\text { 2. Os alunos com NEE } \\
\text { ajustam-se bem quan- } \\
\text { do inseridos em classes } \\
\text { regulares. }\end{array}$ & 6 & $2,4 \%$ & 64 & $25,7 \%$ & 158 & $63,5 \%$ & 21 & $8,4 \%$ \\
\hline $\begin{array}{l}\text { 4. Os alunos sem NEE acei- } \\
\text { tam bem os seus colegas } \\
\text { com NEE. }\end{array}$ & & 11 & $4,4 \%$ & 158 & $63,5 \%$ & 80 & $32,1 \%$ \\
\hline
\end{tabular}


Perceção de professores face à educação de alunos com necessidades educativas especiais: um estudo no norte de Portugal

Continuação quadro 1

\begin{tabular}{l|c|c|c|c|c|c|c|c}
\hline $\begin{array}{l}\text { 7. As necessidades dos } \\
\text { alunos com NEE tornam- } \\
\text { os vulneráveis na classe } \\
\text { regular. }\end{array}$ & 7 & $2,8 \%$ & 76 & $30,5 \%$ & 143 & $57,4 \%$ & 23 & $9,2 \%$ \\
\hline $\begin{array}{l}\text { ll. A liderança numa escola } \\
\text { é essencial para o sucesso } \\
\text { da filosofia inclusiva. }\end{array}$ & & & & & 161 & $64,7 \%$ & 88 & $35,3 \%$ \\
\hline $\begin{array}{l}\text { l3. O professor do ensino } \\
\text { regular deve ser o respon- } \\
\text { sável pela educação de } \\
\text { todos os alunos que tem ao } \\
\text { seu cargo. }\end{array}$ & 16 & $6,4 \%$ & 69 & $27,7 \%$ & 122 & $49,0 \%$ & 42 & $16,9 \%$ \\
\hline $\begin{array}{l}\text { lu. Os alunos com NEE } \\
\text { têm mais sucesso quan- } \\
\text { do inseridos nas classes } \\
\text { regulares. }\end{array}$ & 11 & $4,4 \%$ & 81 & $32,5 \%$ & 138 & $55,4 \%$ & 19 & $7,6 \%$ \\
\hline $\begin{array}{l}\text { 15. Os alunos com NEE } \\
\text { prejudicam os alunos sem } \\
\text { NEE na classe. }\end{array}$ & 30 & $12,0 \%$ & 121 & $48,6 \%$ & 86 & $34,5 \%$ & 12 & $4,8 \%$ \\
\hline $\begin{array}{l}\text { 16. Os professores do ensi- } \\
\text { no regular resistem à ideia } \\
\text { da inserção de alunos com } \\
\text { NEE nas suas classes. }\end{array}$ & 24 & $9,6 \%$ & 118 & $47,4 \%$ & 99 & $39,8 \%$ & 8 & $3,2 \%$ \\
\hline $\begin{array}{l}\text { 20. Os alunos com NEE } \\
\text { têm o direito de frequentar } \\
\text { as classes regulares sempre } \\
\text { que isso seja possivel. }\end{array}$ & 2 & $0,8 \%$ & 3 & $1,2 \%$ & 135 & $54,2 \%$ & 109 & $43,8 \%$ \\
\hline $\begin{array}{l}\text { 21. A minha escola está } \\
\text { preparada para a inclusão } \\
\text { de alunos com NEE. }\end{array}$ & 26 & $10,4 \%$ & 58 & $23,3 \%$ & 132 & $53,0 \%$ & 33 & $13,3 \%$ \\
\hline $\begin{array}{l}\text { 22. Os professores do } \\
\text { ensino regular estão } \\
\text { preparados para responder } \\
\text { às necessidades dos alunos } \\
\text { com NEE. }\end{array}$ & 25 & $10,0 \%$ & 131 & $52,6 \%$ & 85 & $34,1 \%$ & 8 & $3,2 \%$ \\
\hline
\end{tabular}

O primeiro grupo de itens parece revelar que os participantes do estudo concordam com o facto de que todos os alunos têm o direito de aprender em uma classe regular, como mostram os itens 1,14 e 20, nos quais a maioria dos professores $(92,4 \%, 63 \%$ e $98 \%$ respetivamente) concorda ou concorda plenamente com a presença e permanência dos alunos com NEE nas classes regulares, o que permite a convivência com os seus pares sem NEE.

Os participantes reforçam esta opinião ao concordarem com a boa adaptação dos alunos, quando inseridos nas classes regulares. Nos itens 2 e 4 , a maioria dos professores (71,9\% e 95,6\% respetivamente) concorda ou concorda plenamente que os alunos com NEE adaptam-se bem às classes regulares, não havendo problemas de 
convívio com os seus pares sem NEE. A maioria (48,6\%) discorda do facto de que os alunos com NEE possam prejudicar os alunos sem NEE quando inseridos nas classes regulares, como mostra o item 15 .

Os professores parecem reconhecer a importância da sua participação no processo de inclusão de todos os alunos nas suas classes, uma vez que, no item 16, a maioria $(47,4 \%)$ dos participantes afirmou que os professores não são resistentes à inserção de alunos com NEE nas classes regulares. O item 13 vem reafirmar esta postura, visto que $49 \%$ dos professores concorda serem eles os responsáveis por todos os alunos da sua turma.

Porém, reconhecem com clareza a necessidade de não serem os únicos encarregados pela inclusão dos alunos, visto que no item ll, que trata da importância da liderança no processo de inclusão, $100 \%$ dos professores concorda ou concorda plenamente que sem uma boa liderança, a filosofia da inclusão tende a não se concretizar.

No item 7, que afirma que as necessidades dos alunos com NEE podem ficar vulneráveis se incluídos nas classes regulares, $57,4 \%$ dos participantes concordam com esta afirmação, o que leva a refletir sobre a necessidade do trabalho em colaboração com profissionais de diferentes áreas, de acordo com as necessidades do aluno em questão.

Apesar de, no item 21, 53\% dos professores concordarem que a sua escola está preparada para trabalhar de acordo com os princípios da inclusão, 52,6\% declaram, no item 22, que os professores ainda não estão preparados para responder às necessidades dos alunos com NEE, o que reporta à questão da formação e do preparo profissional por eles recebidos.

Este grupo parece descortinar que os professores do ensino regular são a favor da inclusão dos alunos com NEE, sempre que possível nas classes regulares, porém, ainda muito há a ser feito. Destacamos a importância da formação de professores abranger a educação especial no seu currículo, e a participação efetiva da liderança escolar no processo de inclusão educacional.

O segundo grupo de itens, "recursos", explora a questão da equipa interdisciplinar e uma estrutura escolar que favoreça à inclusão de todos os alunos que necessitam de adaptações. O quadro 2 apresenta as frequências absolutas das respostas aos itens $3,5,6,8,12,21,23,24$ e 25. 
Quadro 2-Recursos

\begin{tabular}{|c|c|c|c|c|c|c|c|c|}
\hline Item & \multicolumn{2}{|c|}{ DP } & \multicolumn{2}{|c|}{ D } & \multicolumn{2}{|c|}{ C } & \multicolumn{2}{|c|}{$\mathrm{CP}$} \\
\hline $\begin{array}{l}\text { 3. Os recursos humanos } \\
\text { existentes são suficien- } \\
\text { tes para dar resposta } \\
\text { às necessidades dos } \\
\text { alunos com NEE. }\end{array}$ & 97 & $39 \%$ & 126 & $50,6 \%$ & 20 & $8 \%$ & 6 & $2,4 \%$ \\
\hline $\begin{array}{l}\text { 5. Os professores de } \\
\text { educação especial } \\
\text { correspondem às } \\
\text { expectativas que deles } \\
\text { esperam. }\end{array}$ & 9 & $3,6 \%$ & 48 & $19,3 \%$ & 164 & $65,9 \%$ & 28 & $11,2 \%$ \\
\hline $\begin{array}{l}\text { 6. O processo de aten- } \\
\text { dimento para os alunos } \\
\text { com NEE tem gerado } \\
\text { sucesso. }\end{array}$ & 14 & $5,6 \%$ & 77 & $30,9 \%$ & 151 & $60,6 \%$ & 7 & $2,8 \%$ \\
\hline $\begin{array}{l}\text { 8. Os alunos com NEE } \\
\text { necessitam de mais } \\
\text { atenção do que aquela } \\
\text { que o professor de } \\
\text { ensino regular lhes } \\
\text { pode dar. }\end{array}$ & 4 & $1,6 \%$ & 11 & $4,4 \%$ & 100 & $40,2 \%$ & 134 & $53,8 \%$ \\
\hline $\begin{array}{l}\text { 12. Os serviços espe- } \\
\text { cializados podem fazer } \\
\text { a diferença no sucesso } \\
\text { dos alunos com NEE. }\end{array}$ & 2 &, $8 \%$ & 3 & $1,2 \%$ & 107 & $43 \%$ & 137 & $55 \%$ \\
\hline $\begin{array}{l}\text { 21. A minha escola } \\
\text { está preparada para a } \\
\text { inclusão de alunos com } \\
\text { NEE. }\end{array}$ & 26 & $10,4 \%$ & 58 & $23,3 \%$ & 132 & $53 \%$ & 33 & $13,3 \%$ \\
\hline $\begin{array}{l}\text { 23. A minha escola tem } \\
\text { acesso a recursos, sa- } \\
\text { beres, tempo e práticas } \\
\text { de colaboração para } \\
\text { incluir com sucesso os } \\
\text { alunos com NEE. }\end{array}$ & 15 & $6 \%$ & 110 & $44,2 \%$ & 111 & $44,6 \%$ & 13 & $5,2 \%$ \\
\hline $\begin{array}{l}\text { 24. Aos alunos com } \\
\text { NEE significativas deve } \\
\text { ser-lhes elaborado um } \\
\text { Programa Educativo } \\
\text { Individualizado. }\end{array}$ & 4 & $1,6 \%$ & 5 & $2 \%$ & 82 & $32,9 \%$ & 158 & $63,5 \%$ \\
\hline $\begin{array}{l}\text { 25. Sempre que neces- } \\
\text { sário devem conside- } \\
\text { rar-se ajustamentos e } \\
\text { adaptações curricula- } \\
\text { res para os alunos com } \\
\text { NEE. }\end{array}$ & 5 & $2 \%$ & & & 83 & $33,3 \%$ & 161 & $64,7 \%$ \\
\hline
\end{tabular}


Esse grupo revela que a maioria expressiva $(89,6 \%)$ discorda ou discorda plenamente com o facto de haver, nas escolas do Distrito de Braga, recursos humanos suficientes para que seja possível responder com eficácia às necessidades dos alunos com NEE, explorado no item 3, o que parece transparecer algum conhecimento dos professores frente à necessidade de trabalhar em conjunto. Este fato é reafirmado no item 8 , no qual 94\% dos participantes concorda ou concorda plenamente com o facto de os alunos com NEE poderem necessitar de um conjunto de serviços prestados por professores da educação especial, psicólogos e/ou de outros técnicos especializados.

Em seguimento, no item 12 a maioria (98\%) dos professores concorda ou concorda plenamente com a importância dos serviços especializados, acreditando que estes podem ser decisivos para o sucesso de alunos com NEE. Quanto aos professores de educação especial, no item 5, a maioria dos participantes (65,9\%) parece concordar que estes correspondem às expectativas neles depositadas.

De acordo com os itens 24 e 25 é possível perceber que a massiva maioria dos participantes (96,4\% e 98\% respetivamente) concorda ou concorda plenamente ser essencial a realização de ajustamentos e adaptações curriculares para os alunos com NEE, bem como a elaboração de um Programa Educativo Individualizado (PEI), o que vai de encontro com a investigação.

No item 23, os participantes não são unânimes sobre o preparo das escolas na inclusão de todos os alunos, visto que 44,2\% dos professores discordam, e 44,6\% concordam que a escola, na qual trabalham, tem acesso a recursos, saberes, tempo e práticas de colaboração para incluir com sucesso os alunos com NEE. Este facto parece demonstrar que as escolas do Distrito de Braga ainda não trabalham com uma mesma vertente quando o assunto é a inclusão.

No item 6, 60,6\% dos participantes concordam que o processo de atendimento aos alunos com NEE tem gerado sucesso, o que parece-nos uma informação desencontrada, uma vez que afirmaram no item 3 que os recursos humanos acessíveis nas escolas não parecem ser suficientes para dar resposta às necessidades dos alunos com NEE.

Isto posto, o segundo grupo permite-nos concluir que os participantes reconhecem o mau preparo das escolas em receber os alunos com NEE, visto que não há recursos humanos suficientes para a prática da inclusão.

O quadro 3 expõe a frequência das respostas aos itens 9, 10, 17, 18, 19, 24 e 25 , que perfazem o terceiro grupo de itens em discussão, "colaboração", que expressa a importância do trabalho em colaboração para a efetivação da filosofia da inclusão. 
Quadro 3-Colaboração

\begin{tabular}{|c|c|c|c|c|c|c|c|c|}
\hline Item & \multicolumn{2}{|c|}{$\mathrm{DP}$} & \multicolumn{2}{|c|}{ D } & \multicolumn{2}{|c|}{ C } & \multicolumn{2}{|c|}{$\mathrm{CP}$} \\
\hline $\begin{array}{l}\text { 9. Os professores do ensi- } \\
\text { no regular e de educação } \\
\text { especial devem trabalhar } \\
\text { em parceria. }\end{array}$ & 3 & $1,2 \%$ & 1 &, $4 \%$ & 52 & $20,9 \%$ & 193 & $77,5 \%$ \\
\hline $\begin{array}{l}\text { 10. Os alunos com NEE } \\
\text { têm sucesso desde que } \\
\text { exista um processo que } \\
\text { apele à colaboração entre } \\
\text { professores, profissionais } \\
\text { especializados e pais. }\end{array}$ & & & 15 & $6,0 \%$ & 124 & $49,8 \%$ & 110 & $44,2 \%$ \\
\hline $\begin{array}{l}\text { 17. Os professores do } \\
\text { ensino regular rejeitam a } \\
\text { contribuição de colegas } \\
\text { especializados nas suas } \\
\text { classes. }\end{array}$ & 104 & $41,8 \%$ & 127 & $51,0 \%$ & 15 & $6,0 \%$ & 3 & $1,2 \%$ \\
\hline $\begin{array}{l}\text { 18. Os professores do } \\
\text { ensino regular sentem o } \\
\text { apoio dos professores de } \\
\text { educação especial no que } \\
\text { respeita ao atendimento } \\
\text { dos alunos com NEE. }\end{array}$ & 8 & $3,2 \%$ & 27 & $10,8 \%$ & 175 & $70,3 \%$ & 39 & $15,7 \%$ \\
\hline $\begin{array}{l}\text { 19. Os pais dos alunos com } \\
\text { NEE apoiam o processo } \\
\text { de atendimento às suas } \\
\text { necessidades. }\end{array}$ & 2 &, $8 \%$ & 39 & $15,7 \%$ & 195 & $78,3 \%$ & 13 & $5,2 \%$ \\
\hline $\begin{array}{l}\text { 24. Aos alunos com NEE } \\
\text { significativas deve ser-lhes } \\
\text { elaborado um Programa } \\
\text { Educativo Individuali- } \\
\text { zado. }\end{array}$ & 4 & $1,6 \%$ & 5 & $2,0 \%$ & 82 & $32,9 \%$ & 158 & $63,5 \%$ \\
\hline $\begin{array}{l}\text { 25. Sempre que necessá- } \\
\text { rio, devem considerar-se } \\
\text { ajustamentos e adaptações } \\
\text { curriculares para os alunos } \\
\text { com NEE. }\end{array}$ & 5 & $2,0 \%$ & & & 83 & $33,3 \%$ & 161 & $64,7 \%$ \\
\hline
\end{tabular}

Esse grupo é-nos esclarecedor, visto que no item 9, a expressiva maioria (98,4\%) dos participantes concorda ou concorda plenamente que o trabalho em parceria entre professores do ensino regular e da educação especial é extremamente necessário. No item 10,94\% dos professores reconhecem que, quando há um trabalho em colaboração, os alunos com NEE tendem a experienciar sucesso. 
Os participantes do estudo consolidam esta ideia quando no item 17, 92,2\% discordam ou discordam plenamente com o facto de que os professores do ensino regular rejeitam a participação/contribuição dos outros profissionais especializados nas suas classes. No seguimento, os professores reforçam a sua opinião quando, no item 18 , a maioria $(78,3 \%)$ concorda que os professores do ensino regular sentem-se apoiados pelos professores da educação especial no atendimento a alunos com NEE.

De facto, não é certo considerar a colaboração apenas entre professores do ensino regular e da educação especial. É necessária a formação de uma equipe interdisciplinar que atenda às necessidades dos alunos, sempre com o envolvimento parental. Os participantes demonstraram concordar com esta premissa, pois, no item 19 , a maioria $(78,3 \%)$ concorda que os pais têm apoiado o processo de atendimento às necessidades dos seus filhos.

Em teoria, os participantes demonstram conhecer o que é defendido pela investigação, e confirmam a necessidade de elaborar um PEI para os alunos com NEE significativas, que aborde todas as suas necessidades e capacidades, com o devido acompanhamento da sua evolução.

\section{Análise Inferencial}

Para a análise inferencial, que apresentamos a seguir, realizamos testes paramétricos para dois grupos (Teste T-student), para a variável gênero. Para os 25 itens foram testadas as seguintes hipóteses:

Hl: Há diferenças significativas nos grupos de acordo com o gênero dos participantes.

HO: Não há diferença significativa nos grupos de acordo com o gênero dos participantes.

A homogeneidade de variâncias nos grupos foi avaliada com o teste de Levene $(F=29,554 ; t=-4,174 ; p=0,000 ; d=0.69)$ e foram encontradas diferenças significativas no item 10, havendo homogeneidade nos outros 24 itens. Os participantes do gênero masculino $(\mathrm{M}=3.06$; $\mathrm{DP}=528)$ tiveram uma média inferior quando comparados aos do gênero feminino (M=3,45; DP=.59l). Logo, rejeita-se a HO e aceita-se a Hl.

Na aplicação do teste ANOVA foram testadas as seguintes hipóteses:

Hl: Há diferenças significativas nos grupos de acordo com as habilitações dos participantes.

HO: Não há diferenças significativas nos grupos de acordo com as habilitações dos participantes.

$\mathrm{Na}$ análise das perceções entre os seis subgrupos de habilitações académicas, nomeadamente magistério, bacharelado, licenciatura, especialização, mestrado e doutoramento verificou-se uma diferença estatisticamente significativa entre os par- 
ticipantes com Doutoramento e as demais habilitações nos itens $1(F(1,266)=3,059 ; p=$ 0,$011 ; \eta^{2}=.059$; potência $\left.(\pi)=.865\right), 6\left(F(1,266)=2,998 ; p=0,012 ; \eta^{2}=.058\right.$; potência $(\pi)=.856), 7\left(F(1,266)=3,480 ; p=0,005 ; \eta^{2}=.067\right.$; potência $\left.(\pi)=.910\right), 13(F(1,266)$ $=3,382 ; \mathrm{p}=0,006 ; \eta^{2}=.065$; potência $\left.(\pi)=.901\right), 16\left(F(1,266)=4,088 ; p=0,001 ; \eta^{2}\right.$ $=.078$; potência $(\pi)=.952), 17\left(F(1,266)=2,764 ; p=0,019 ; \eta^{2}=.054\right.$; potência $(\pi)=.823$ ) e $19\left(F(1,266)=3,112 ; p=0,010 ; \eta_{p}{ }^{2}=.060\right.$; potência $\left.(\pi)=.872\right)$. Desse modo, é possível rejeitar a hipótese nula.

Também foi aplicada a ANOVA para as seguintes hipóteses:

Hl: Há diferenças significativas nos grupos de acordo com a experiência profissional dos participantes.

HO: Não há diferenças significativas nos grupos de acordo com a experiência profissional dos participantes.

$\mathrm{Na}$ análise das perceções entre os 7 subgrupos, nomeadamente menos de 5 anos, entre 5 e 10 anos, entre 11 e 15 anos, entre 16 e 20 anos, entre 21 e 25 anos, entre 26 e 30 anos, e mais de 30 anos, verificamos diferenças significativas nos itens 5 ( $F$ $(6,242)=2,528 ; p=0,022 ; \eta^{2}=.059 ;$ potência $\left.(\pi)=.837\right) ; 6(F(6,242)=2,279 ; p=0,037$; $\eta_{p}^{2}=.053$; potência $\left.(\pi)=.790\right) ; 9\left(F(6,242)=3,142 ; p=0,006 ; \eta_{p}^{2}=.072\right.$; potência $(\pi)=$ $.917)$; e ll $\left(F(6,242)=2,899 ; p=0,010 ; \eta_{\mathrm{p}}{ }^{2}=.067\right.$; potência $\left.(\pi)=.891\right)$. Desse modo, é possível rejeitarmos a hipótese nula.

\section{Conclusão}

Os resultados desse estudo levam-nos a concluir que os sujeitos consideram importante que a implementação da filosofia inclusiva em Portugal não descure fatores como a colaboração, a efetuação de adaptações curriculares, a elaboração de programas educativos individualizados eo envolvimento parental na educação de alunos com NEE, fatores aliás considerados no vasto caudal de literatura existente sobre o assunto. Dettmer, Dick e Thurston (1999) enfatizam a necessidade do trabalho em colaboração, afirmando que as metas da inclusão não serão atingidas caso ele não se processe. Também Correia (2008) e Hallahan e Kauffman (1991), ao reportarem-se à colaboração, evidenciam a sua importância na formação de equipas de apoio ao aluno e de equipas interdisciplinares conducentes à elaboração de respostas educativas eficazes para os alunos com NEE. Porém, os participantes revelam que não há recursos humanos suficientes nas escolas para que seja possível criar estas equipas de forma a poderem responder às necessidades de todos os alunos com NEE inseridos nas escolas regulares. A investigação sugere, ainda, que o envolvimento parental pode, muitas vezes, constituir a diferença entre o sucesso e o insucesso de determinado programa e, consequentemente, entre o sucesso e o insucesso da criança nele envolvida (MANDELL\& FISCUS, 1981; SWICK, 1987).

Os resultados indicam, também, que os professores são a favor da presença de alunos com NEE nas classes regulares, uma vez que a convivência com os seus pares sem NEE poderá ser uma mais-valia para ambos os grupos. Essa conclusão vai ao encontro ao que defende Correia que, ao expor o seu modelo de inclusão progres- 
siva, afirma que, "sempre que possível, os alunos com NEE devem receber todos os serviços de que necessitam nas classes regulares das escolas das suas residências." (2008, p.23)

Nesse estudo, torna-se ainda explícito que os participantes concordamque a responsabilidade primeira de atender às necessidades de todos os alunos é dos professores do ensino regular. Entretanto, como vimos atrás, ao tratar-se de crianças com NEE poderá ser necessária uma série de adequações curriculares para as quais o professor do ensino regular poderá não estar preparado, sendo, nestes casos, necessária a colaboração de outros agentes educativos, particularmente a do professor de educação especial.

Finalmente, com base nas conclusões desse estudo, para que a filosofia da inclusão possa vir a implementar-se com sucesso nas escolas do país, é fundamental que se considere um conjunto de medidas, das quais destacamos a eficácia da liderança, a colaboração, a utilização de estratégias de aprendizagem baseadas na investigação, as adaptações curriculares, o envolvimento parental e os recursos especializados (CORREIA, 2008). Consideramos que sem estas medidas não será possível promover uma educação de qualidade para todos os alunos tal como é proclamado pelo movimento da inclusão. Contudo, como nos alerta Correia (2008), mais de metade dos alunos com NEE em Portugal não recebem, neste momento, uma educação apropriada às suas necessidades, uma vez que a maioria das premissas supracitadas não estão a ser respeitadas. Assim sendo, de acordo com os resultados deste estudo, seria aconselhavel que o sistema promovesse uma reflexão com vista a uma melhor formação de todos os envolvidos na educação de alunos com NEE, bem como impulsionasse um diálogo profícuo entre todos os agentes educativos, pais e comunidade em geral, no sentido de se repensar a legislação existente.

\section{Referências}

CORREIA, L. M. A escolar contemporânea e a inclusão de alunos com NEE: Considerações para uma educação com sucesso. Porto: Porto Editora, 2008.

Alunos com necessidades educativas especiais nas classes regulares. Porto: Porto Editora, 1997a. 7-10, 1997b.

Só existe uma educação: Admitir uma regular e uma especial é um erro. Escola Informação, 129,

CORREIA, L. M; MARTINS, A. P. Uma escola para todos: Atitudes dos professores perante a inclusão. In: CORREIA, L. M. (Org.). Inclusão, Porto, n.1, p. 17-28, 2000.

DETTMER, P.; DYCK, N.; THURSTON, L. P. Consultation, collaboration, and teamwork for students with special needs. 3.ed. Allyn\& Bacon, 1999.

HALLAHAN, D. P.; KAUFFMAN, J. M. Exceptional children: Introduction to special education. 5.ed. New Jersey: Prentice Hall, Englewood Cliffs, 1991.

HEWARD, W. L. Ensino e aprendizagem: dez noções enganadoras limitativas da eficácia da educação especial. In: CORREIA, L. M. (Org.). Educação especial e inclusão: Quem disser que uma sobrevive sem a outra não está no seu perfeito juízo. Porto, n. 13, p. 109-153, 2009. 
MENDELL, C.; FISCUS, E. Understanding exceptional people. St. Paul, MN. West, 1981.

SWICK, K. Perspectives on understanding and working with families. Champaing: IL, Stipes, 1987.

WARNOCK, M. Special educational needs: A new look.London: Philosophy of Education Society of Great Britain, 2005.

\section{Correpondência}

Amanda Fernandes Santos - Univerisade do Minho, Largo do Paço, CEP: 4704-553, Braga, Portugal.

E-mail: amandafernande@gmail.com - lmiranda@ie.uminho.pt - acs@ie.uminho.pt

Recebido em 23 de maio de 2013

Aprovado em 12 de novembro de 2013 
